\title{
EFFICIENCY IMPROVEMENT THROUGH TOTAL PRODUCTIVE MAINTENANCE
}

\section{USMAN GHANI, HAMID MINHAS}

Department of Mechanical Engineering UET Peshawar, Pakistan

\begin{abstract}
Overall Equipment Efficiency (OEE) is a parameter used to achieve certain goals in manufacturing and finding the base for direct and sustainable improvements. In global manufacturing, the OEE has gained large acceptance. It is basically one of the results of long term evaluation of the Total Productive Maintenance (TPM) concept. Total Production Manufacturing is nowadays a widely accepted concept for continuous improvement in the industry. Maximization of the efficiency of equipment means to reduce the losses that affect the efficiency of equipment. Losses are, in fact classified into various categories and in the case of TPM activity in Industries; a very minute classification is done. Generally, equipment related losses are classified into two categories: Unforeseen losses and chronic losses. It is an easy decision to implement counter measures for unforeseen losses as onetime loss is very big. On the other hand, in case of chronic losses, even though the loss per time is not that big but since they accumulate to a big amount in regular operation, they should not be neglected. This research will focus on the causes of major losses and countermeasures to decrease performance losses, hence contributing to OEE improvement. This research will enable industries to understand the implementation procedures of TPM practices. The implementation of TPM methodology has shown good results across the machine unit and their performance has improved.
\end{abstract}

KEYWORDS: OVERALL Equipment Efficiency, Total Productive Maintenance, Losses, Measures, Equipment

Received: Jan 14, 2021; Accepted: Feb 05, 2021; Published: Feb 13, 2021; Paper Id.: IJMPERDAPR20213

\section{INTRODUCTION}

OEE is a technical Key Performance Indicator (KPI) to achieve set goals in manufacturing such as direct and sustained improvements. It has direct impact on increasing the productivity of systems. In global manufacturing, the OEE has gained large acceptance. The OEE has been first defined by the Japan Institute of Plant Maintenance [1]. It was one of the results of long term evaluation of the TPM concept, which has been spread over the world. Producing better quality and cost-effective products is a key to remain competitive globally. TPM tools assist to eliminate any wastages in manufacturing processes and produce quality and economical products. Plant maintenance is an important area in manufacturing where high percentage of manufacturing cost is associated with different maintenance activities [2]. Among various industries, high demand items production plants particularly in Pakistan are not working to desired productivity level, which is due to downtime and ill-planned maintenance procedures and processes. Productivity in industries can be enhanced through capturing the maintenance and breakdown processes [3]. The processes can be captured and visualized to the very low level of maintenance. Various TPM techniques such as Pareto analysis, process chart are developed for the existing processes. Any suggested improvements in processes will be observed once the selected industrial case implements it. All this research exercise will enable industries to understand implementation procedures of TPM practices. 
OEE is a hierarchy of metrics which evaluate how effectively a manufacturing operation is practiced [4]. If for example the cycle time is reduced, the OEE will increase, i.e. more product is produced for less resource. OEE breaks the performance of a manufacturing unit into three separate but measurable components: Availability, Performance, and Quality. Each component points to an aspect of the process that can be targeted for improvement. OEE may be applied to any individual Work Center, or rolled up to department or Plant levels. This tool also allows to drill down to very specific analysis, such as a particular Part Number, Shift as an example. It is unlikely that any manufacturing process can run at $100 \%$ OEE. Many manufacturers benchmark their industry to set a challenging target; $85 \%$ is common [5]. The availability portion of the OEE Metric represents the percentage of scheduled time that the operation is available to operate. The Availability Metric is a pure measurement of uptime that is designed to exclude the effects of Quality, Performance, and unscheduled downtime events. The losses due to unavailability is called availability losses [6]. The performance portion of the OEE metric (also known as process rate) represents the speed at which the work center runs as a percentage of its designed speed. The Performance Metric is a pure measurement of speed that is designed to exclude the effects of Quality and Availability. The losses due to wasted performance are also often called speed losses. In practice it is often difficult to determine speed losses, and a common approach is to merely assign remaining unknown losses as speed losses [7].

The quality portion of the OEE Metric represents the good units produced as a percentage of the total units started. The Quality Metric is a pure measurement of process yield that is designed to exclude the effects of availability and performance. The losses due to defects and rework are called quality losses [8]. OEE covers the Availability, Performance and quality of manufacturing process $[9,10]$. There are various causes which affect the productivity such as environment, methods, machines, personals, material and measurements. Among all these machines are mostly unpredictable resource and causes variability in overall production. Therefore this research is broadly focused on the study of machines high rate of minor stops and chronic issues not resolved over time leading to dip in machine's efficiency.

\section{LITERATURE REVIEW}

Different researchers have worked on the improvement of industries by applying the TPM techniques. Few of the relevant state of art knowledge background has been discussed in this chapter to give idea that how different researchers have applied TPM in different industrial sectors. This research will benefit industry and academics in terms of measures of efficiency. The results may be useful to compare OEE of this industry with other particular industries. The research is significant as it is based on actual problem of industry and will improve the efficiency of a set of machines thereby increasing the production rate of the product. Gupta et al. studied to give insight into how increase in manufacturing performance in terms of sales volume has taken place with improvement in OEE, productivity and production cost. OEE proved to be a valuable tool that helped the management in improving the process capabilities and operational effectiveness of the plant equipment. The OEE of all machines got improved above 85\% level [10]. Generally, the OEE measure is treated as an important indicator of the success of TPM program. The work demonstrates an innovative use of OEE as a tool for improving operational effectiveness of all the machines under TPM consideration. Study also summarizes that OEE is not the only productivity improvement criteria whereas capacity building through improvement projects or technology up gradation with capital investment also contributed in escalating productivity. A company achieved notably tangible and intangible benefits with the TPM implementation. The company continued its TPM journey to achieve higher levels of improved manufacturing performance. 
Tenera et al. [11] gave an improvement model supported by the DMAIC cycle and integrating an enlarged and adapted set of statistical tools, given the nature of the project main variables and the involved processes. The proposed model permitted to systematically address the actions and solutions to be implemented in order to keep, in the long run, the continuous improvement of the project management processes in the organization. Yousouf et al. [12] research work focuses on the optimization of maintenance for industrial systems by the use of Lean six Sigma bases. Lean Six Sigma is a method of improving the quality and profitability based on mastering statically of process and it is also a management style that based on a highly regulated organization dedicated to managing project. The method is based on five main steps summarized in the acronym (DMAIC): Define Measure, Analyze, Improve and Control. Application of the method on the maintenance processes with using maintenance methods during the five phases of the method will help to reduce costs and losses in order to strive for optimum results in terms of profit and quality. Khaled et al. [13] discusses how to route straddle carriers in port container terminals. This problem is solved in the context of optimizing transport operations. The contribution of the work lies in the formulation and subsequent development of a Six Sigma Approach solution for the problem. Generating and prioritizing the critical Six Sigma transportation plans, however, are real challenges in practice. In this study an empirical case study is used to explore the effectiveness of the proposed approach.

Surendro et al. [14] studies reveals that Six Sigma could be used for reducing information variance in healthcare, especially information that used in Hospital Information System. Information quality is a key element to determine the level of healthcare in hospital. By the improvement of information quality, the quality of healthcare would improve to support the patient's satisfaction. A method used for information quality improvement is Six Sigma. Y.Maha et al. [15] studies reveals attempts to figure out the relationship between Six Sigma, innovation performance, and examine the mediating role of $\mathrm{AC}$ in the relationship matrix. A questionnaire was used to collect the data from the manufacturing companies in Malaysia and Partial Least Square techniques were adopted to analyze the data obtained. Based on the literature review, the conceptual framework of this study was introduced. The quality level measurement of a given process is essential to some phases of six sigma methodology. J.Christyanti et al. [16] have done research in Indonesia in which many housing constructors are using asbestos as roofing. Before the initiative was conducted, the sigma level was at 4.91 sigma with defects per million (DPMO) level at 200 units. By implementing six sigma methodologies, the team found that this condition was mainly caused by side flat as its dominant defect type due to speeding up the curing time without simultaneously increasing its temperature .

R. Pamfilie et al. [17] demonstrated that organizations can obtain individual and organizational performance by using well trained leaders focused on continuous improvement which use Lean Six Sigma in driving employee synergy. The findings of this paper revealed the key factors needed to create a special framework which can lead the organization to business excellence through personnel improvement. This approach can be used by any organization and has the purpose to develop strategic business objectives and to highlight the importance of personal improvement. Rosenzweig et al. [18] studies the role of individual experience, organizational experience, team leader experience, and experience working together on a team in the context of improvement teams. To do so, analysis was carried by six sigma improvement team projects at a Fortune 500 consumer products manufacturer with multiple business groups. Such improvement project teams focus on deliberate learning. Of the four experience variables we study, we find that team leader experience exhibits the strongest relationship with project success, followed by organizational experience. Further, in contrast to prior related research on work teams, we find no relationship between individual experience or team familiarity and project success beyond that explained by team leader and organizational experience. R.Gonzalez et al. [19] have done research work which 
proposes the application of Six Sigma methodology for improving energy efficiency in a distillation unit of a naphtha reforming plant. The results reproduce the past Energy performance of the unit through multivariate models and show optimal operation mode with an expected savings around 150,000€/year.

Haslinda et al. [20] study show that there is a significant and positive relationship between the implementation of TPM practices at the semiconductor company in Malaysia. The improvement in the OEE rates was witnessed in the organization. The study proved that with established of TPM, the overall equipment effectiveness improved from $68.9866 \%$ respectively before TPM implementation to $71.465 \%$ respectively after TPM implementation. Rabby et al. [21] study shows that successful implementation of TPM plays a very important role in fastener or any manufacturing industries to find out and eliminate various types of losses. It also helps the management to improve the overall performance of the firm including all levels of people OEE indicates the improvement of TPM implementation. For this study OEE has increased from $51.93 \%$ to $60.35 \%$ indicating the improvement of availability rate, performance rate and quality rate and reduce the unnecessary usages of properties. Amrik et al. [22] findings are that the implementation of OEE is typically based on the motivation to use OEE as a basic reference measure for analyzing the utilization of the resources at the plant. For firms with multiple plants, a motivation has also been to be able to compare plants based on OEE. Sharma et al. [23] study proved that TPM leads to increase in efficiency and effectiveness of manufacturing system in term of OEE index. N.Gera et al. [24] research also supports the view that by adopting Six Sigma the variability in a process will be reduced. In addition to the direct savings which are achieved by improved quality and reduced scrap, the organization can also be benefited from the indirect savings such as in lower rework cost, minimum product recalls, low warranty liabilities.

Many researcher have used statistical tools to bring improvement in different industries. Despite the increased number of papers discussing the adoption of TPM in the service sector internationally in the last few years, the detailed implementation in Small and Medium Enterprises (SMEs) especially in Pakistan was not done. Existing Literature findings support the view that despite TPM is considered as a fully developed methodology, further research is needed to establish a more systematic approach to help companies, and especially SMEs embark on TPM projects. Implementation of TPM practices are not a routine in Industries of Pakistan. Therefore, a very less research work is available related to specific industry with regards to optimum utilization of equipment. Manufacturing industry is a highly revenue generating industry all over the world as well in Pakistan, whereas its production is not optimum as per the requirements. The cost effective way is to analyze the production processes on the lines of other industries and improve the existing machines instead of installing new machines in order to enhance the production rate.

\section{METHODOLOGY}

The methodology that is adopted to carry out the research has been discussed. Complete research process is done is four stages which is shown as a flow chart in figure 2. In first stage data is collected, machine performances are measured and OEE measurements are done. In second stage, data analysis is done as per the cause and effect diagram. In third stage an action plan is devised to resolve the issues and in fourth stage, verification of action plan and continuous improvement is ensured. 


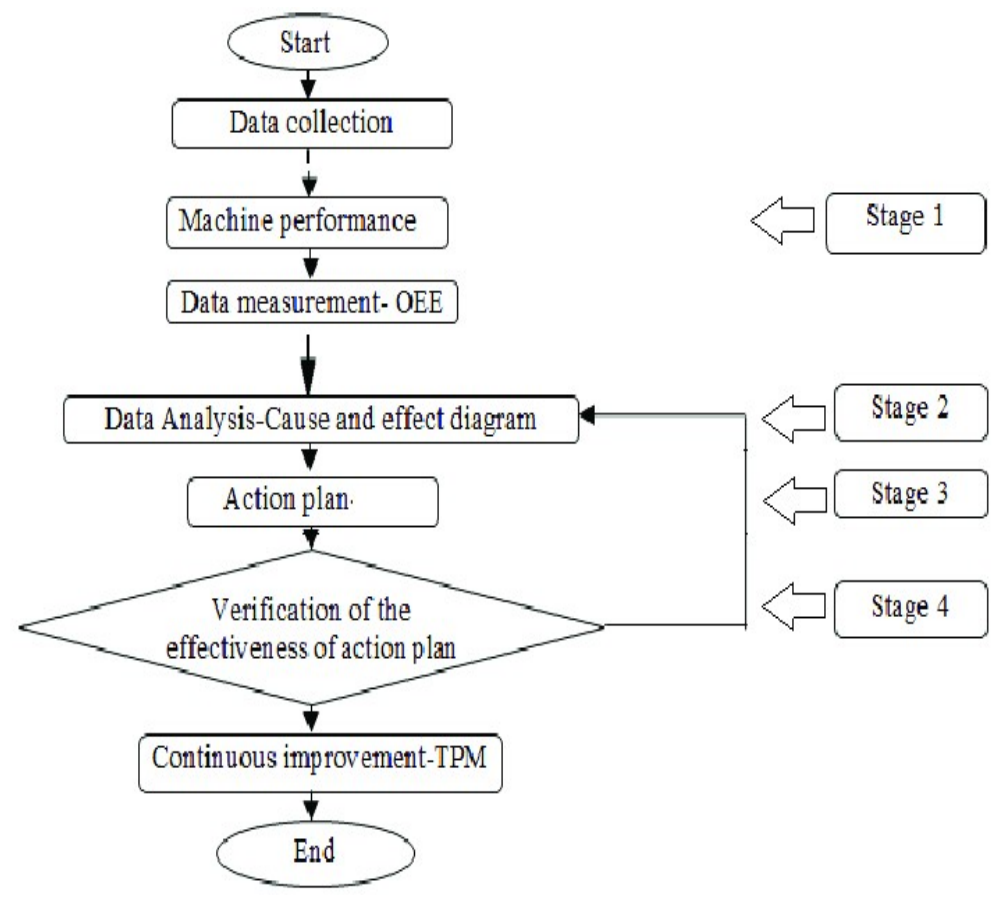

Figure 1: Methodology flow chart of the research.

The methodology used in this research is TPM methodology of Define, Measure, Analyze, Improve and Control known as "DMAIC “ The DMAIC project methodology has five phases [25]. Methodology is to measure Net Operating Rate losses on account of stoppages that hamper Performance Efficiency using the TPM methodology; determine improvement opportunities and develop Control Strategy for sustainability of determining factors in the 'Improve Phase'. For this purpose, machine cell of manufacturing plant has been selected which comprises of 5 machines in a row.

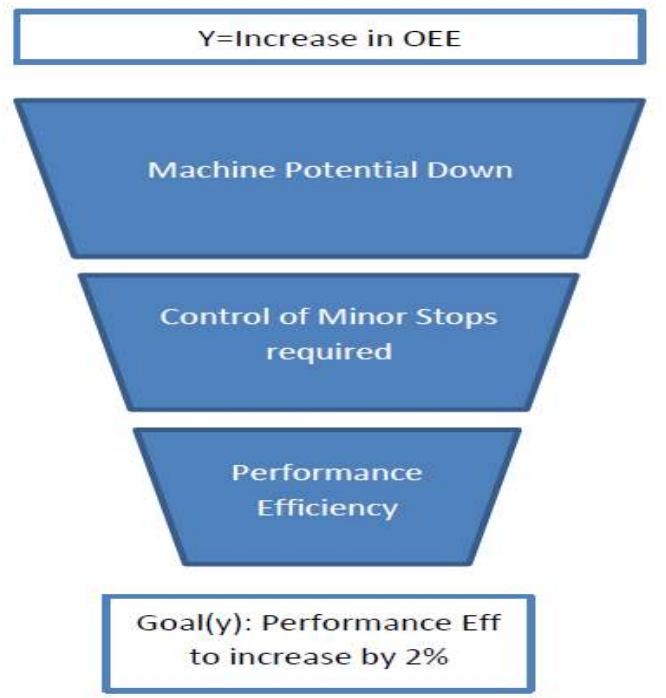

Figure 2: Steps to achieve the goal in terms of performance efficiency.

These steps broadly define the steps required to be taken in terms of variable "Y" and and reach our goal "y". Following these steps in sequence will lead to achieving our goal. The sources of stoppages in machine are identified and categorized as per the nature of cause which affects the performance efficiency. A data collection plan will be developed to 
formulate location, collection and organization of performance trends. This data will be used for following purposes:

- To identify measure of dispersion

- To determine current process capability

- To identify major variation / losses

\subsection{Process Measurement}

Process Measurement is carried out that entails total downtime and stoppage frequency of 60 days of machine running, however for analysis and improvement phases of priority areas, Simple Random Sampling is used to determine (randomly) 30 days of data for study purposes. After analyzing the data using box plots, pareto analysis, data is further grouped and stratified in terms of stoppage frequency and corresponding downtime for each day. Stoppages with recurring values and significant stoppage time are considered for analysis phase, while the rest is deemed insignificant. Henceforth, the stoppages which are identified that are major and impactful in the process from initial screening and their effects are analyzed to establish significance on Machine Performance Efficiency. From the results of analysis, a dedicated improvement plan is made to reduce the stoppages and to improve the OEE.

\section{IMPROVEMENTS}

The main cause of failures in systems is poor maintenance. In order to avoid premature failures, maintenance at regular intervals is vital. The goal of maintenance in a system is maintaining its reliability, reducing total operating cost, extending equipment lifetime, using different types of maintenance strategies. Two type of maintenances have been suggested. First is Preventative maintenance is maintenance that is regularly performed on a piece of equipment to lessen the likelihood of it failing. Preventative maintenance is performed while the equipment is still working, so that it does not break down unexpectedly. Second is Breakdown maintenance is a form of material or equipment remediation that is performed after the equipment or material has lost its functioning capabilities.

\subsection{Line Improvement Plans}

Carrying forward the facts established from previous section, the focus of improvement was resultantly zeroed down to improvement of module A and B, where the pareto of each line was observed in detail which revealed the key issues. Based on these issues a dedicated improvement plan was made for these lines to improve the OEE of these lines. For line A and $\mathrm{B}$, the following plan was made as given in table 2 and 3 respectively.

Table 2: Maintenance plan for Module A

\begin{tabular}{|l|l|l|l|l|}
\hline Area & Sub Area & \multicolumn{1}{|c|}{ Issues } & \multicolumn{1}{c|}{ Solution } & \multicolumn{1}{c|}{ Responsibility } \\
\hline \multirow{3}{*}{ X3 } & AM-14 & $\begin{array}{l}\text { Link up conveyor setting } \\
\text { required in case of maker } \\
\text { not running }\end{array}$ & $\begin{array}{l}\text { Maker run signal } \\
\text { synchronization with } \\
\text { packer }\end{array}$ & Electrical team \\
\cline { 2 - 5 } & \begin{tabular}{l} 
Potentio meter setting \\
\cline { 2 - 5 }
\end{tabular} & $\begin{array}{l}\text { Popper door cylinder } \\
\text { should be replaced }\end{array}$ & Cylinder replaced & Mechanical team \\
\hline
\end{tabular}




\begin{tabular}{|c|c|c|c|c|}
\hline & & Al. Foil jamming & Unit serviced & Mechanical team \\
\hline & $\begin{array}{l}\text { Foil down } \\
\text { Feed }\end{array}$ & $\begin{array}{l}\text { Al Foil splicing out of } \\
\text { order } \\
\text { Setting required on A side }\end{array}$ & $\begin{array}{l}\text { Adjusted the sensor } \\
\text { and parameter }\end{array}$ & Electrical team \\
\hline & $\begin{array}{l}\text { Blank } \\
\text { Transport }\end{array}$ & Servicing required & Serviced & Mechanical team \\
\hline $\mathrm{CT} / \mathrm{CV}$ & CV Exit & CV overwrap missing issue & U-knife replaced & Mechanical team \\
\hline Panel & Electrical & $\begin{array}{l}\begin{array}{l}\text { Frequently } \\
\text { operated }\end{array} \\
\text { NOT }\end{array}$ & $\begin{array}{l}\mathrm{CV} \text { emergency stop } \\
\text { button replaced }\end{array}$ & Mechanical team \\
\hline Quality & $\begin{array}{l}\text { Quality } \\
\text { Issues }\end{array}$ & Outer unstuck issue & $\begin{array}{l}\text { Knife replacement / } \\
\text { Sensor adjustment }\end{array}$ & $\begin{array}{l}\text { Mechanical / Electrical } \\
\text { team }\end{array}$ \\
\hline
\end{tabular}

Table 3: Maintenance plan for Module B

\begin{tabular}{|c|c|c|}
\hline S/No & Task & Responsibility \\
\hline 1 & Al Foil splicing issue at high speed. Check scissor cutting & Mechanical Team \\
\hline 2 & Blank glue nozzle issue. To be replaced. & Mechanical Team \\
\hline 3 & Blank glue level check mounting issue. To be fixed. Loose in bracket & Mechanical Team \\
\hline 4 & End of ICB reel sensor. Fix mechanical lever. & Electrical Team \\
\hline 5 & Set glue application, gluer contrast worn spots & Mechanical Team \\
\hline 6 & Remove packing from End of CV TOR sensor & Electrical Team \\
\hline 7 & Replace oil seal turret packet extractor & Mechanical Team \\
\hline 8 & Blank transfer right side guide oil leakage & Mechanical Team \\
\hline 9 & Pack formation issue to be resolved & Mechanical Team \\
\hline 10 & Code unit replacement required. Grooves in screws heads & Mechanical Team \\
\hline 11 & Blank glue application is improper causing $5^{\text {th }}$ wheel jamming & Mechanical Team \\
\hline 12 & Turret holding clamping screw causing turret let out of position & Mechanical Team \\
\hline 13 & End of inner frame reel check sensor not working. Mechanical issue & Mechanical Team \\
\hline 14 & B side. Al foil left over issue. Setting required & Mechanical Team \\
\hline 15 & AM14 upper link contrast top belt half broken. Replacement required & Mechanical Team \\
\hline 16 & $1^{\text {st }}$ channel guard problem, restricts access to $1^{\text {st }}$ channel. Fined alternate & Mechanical Team \\
\hline 17 & CV TOR sensor not functional. Mechanical issue & Electrical Team \\
\hline
\end{tabular}

\subsection{Results}

Based on implementation of the above mentioned improvement plans and DOE, the results were observed over a span of 2 months. Since the focus of improvement was module 5 and module 7 , individual OEE results are appended here first as shown in figure 3 , followed by the results of the cell. 


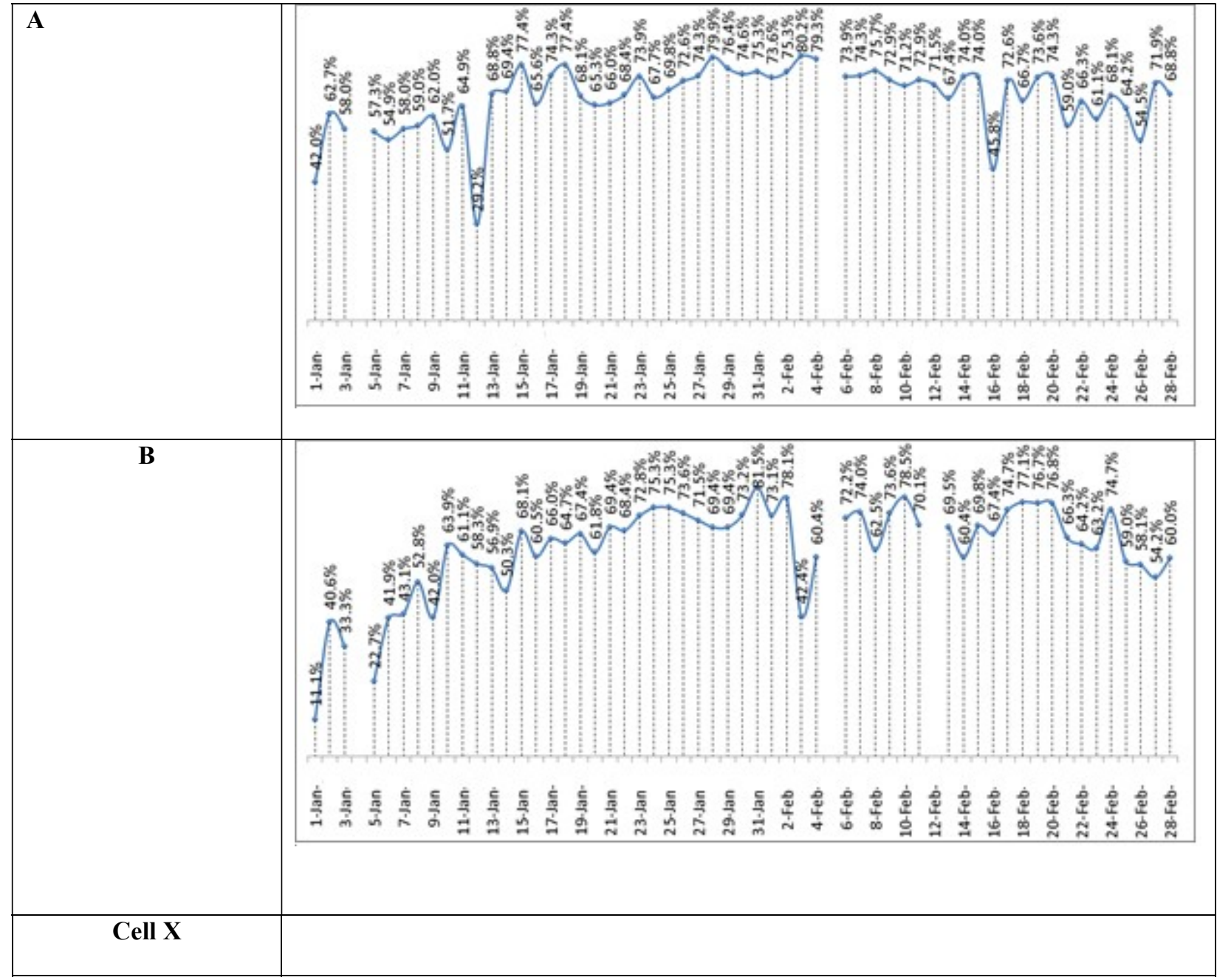

Figure 3: OEE results after improvements.

From the above graphical OEE results it can be clearly seen that both the modules shows improvement trend in the first half of the month, translating into increased OEE for the Cell for the 2 months.

\section{CONCLUSION AND FUTURE WORK}

Based on the results shown above, it can be seen that using the TPM methodology, performance results can significantly be improved, through a systematic approach. This research has helped to understand the OEE concept and different types of losses in manufacturing machines. The results may be useful to compare OEE of this industry with other particular industries. The OEE has increased from $67 \%$ to $72 \%$, saving approximately PKR 10 million. If monitored daily using emerging digital technologies like OEE dashboard and machine learning techniques then proactive decisions can be taken in shop floor to improve plant OEE. OEE should be used as a metric to identify opportunities of improvement. Thus, OEE must be used as a continuous Improvement tool that should be used to evaluate every component that can be improved.

\section{REFERENCES}

1. Nakamura T. Total productive maintenance. Encyclopedia of Statistics in Quality and Reliability. 2008 Mar 15;4.

2. McKone KE, Schroeder RG, Cua KO. The impact of total productive maintenance practices on manufacturing performance. Journal of operations management. 2001 Jan 1;19(1):39-58. 
3. Muchiri P, Pintelon L. Performance measurement using overall equipment effectiveness (OEE): literature review and practical application discussion. International journal of production research. 2008 Jul 1;46(13):3517-35.

4. Raguram R. Implementation of Overall Equipment Effectiveness (OEE). Middle-East Journal of Scientific Research. 2014;20(5):567-76.

5. Lõun K, Riives J, Otto T. Evaluation of the operation expedience of technological resources in a manufacturing network. Estonian Journal of Engineering. 2011 Mar 1;17(1):51.

6. Dal B, Tugwell P, Greatbanks R. Overall equipment effectiveness as a measure of operational improvement-a practical analysis. International Journal of Operations \& Production Management. 2000 Dec 1;20(12):1488-502.

7. Sandengen OC, Estensen LA, Rødseth H, Schjølberg P. High Performance Manufacturing-An Innovative Contribution towards Industry 4.0. In6th International Workshop of Advanced Manufacturing and Automation 2016 Nov 10. Atlantis Press.

8. Vijayakumar SR, Gajendran S. Improvement of overall equipment effectiveness (OEE) in injection moulding process industry. IOSR J Mech Civil Eng. 2014;2(10):47-60.

9. Sowmya K, Chetan N. A review on effective utilization of resources using overall equipment effectiveness by reducing six big losses. International Journal of Scientific Research in Science, Engineering and Technology. 2016;2(1):2394-4099.

10. Gupta, Pardeep, and Sachit Vardhan. "Optimizing OEE, productivity and production cost for improving sales volume in an automobile industry through TPM: a case study." International Journal of Production Research 54.10 (2016): 2976-2988.

11. Alexandra Tenera, Luis Carneiro Pinto (2014). UNIDEMI, Mechanical and Industrial Engineering Department, Caparica, 2829-516, Portugal vol.119, pp 912-920.

12. Ayadi Youssouf, Chaib Rachid (2014). Badji Mokhtar university, Annaba laboratory environment and transport engineering. Mentouri university, Roumania, vol. 55 , pp $512-518$.

13. Khaled Mili (2014). Higher Institute of Business Administration of Gafsa, Jemmel 5020, Tunisia vol.111, pp-1195-1205

14. Ratnaningtyas, Dyah Diwasasri, and Kridanto Surendro. "Information quality improvement model on hospital information system using six sigma." Procedia Technology 9 (2013): 1166-1172.

15. Maha Yusr, (2012). Kolej Maybank, University Utara Malaysia UUM, 06010, Sintok, Kedah, Malaysia vol. 65, pp 570 - 578.

16. Jonnya and Jessika Christyanti (2012). Universitas Bina Nusantara, Jl. K.H. Syahdan No. 9, Palmerah, Jakarta, 11410, Indonesia vol. 65 pp $306-312$.

17. Rodica Pamfiliea, (2012). The Bucharest Academy of Economic Studies, Bucharest, 010374, Romania vol. 58, pp 187 - 196.

18. R. González Falcón (2012). Improving Energy Efficiency in a Naphtha Reforming Plant Using Six Sigma Methodology, Fuel Processing Technology 103 (2012), pp 110-116.

19. R. González Falcón (2012). Improving Energy Efficiency in a Naphtha Reforming Plant Using Six Sigma Methodology, Fuel Processing Technology 103 (2012), pp 110-116.

20. Fam, S. F., Loh, S. L., Haslinda, M., Yanto, H., Khoo, L. M. S., \& Yong, D. H. Y. (2018). Overall Equipment Efficiency (OEE) Enhancement in Manufacture of Electronic Components \& Boards Industry through Total Productive Maintenance Practices. In MATEC Web of Conferences (Vol. 150, p. 05037). EDP Sciences.

21. Rahman, M. S., M. A. Islam, and M. N. I. Rabby. "Implementation of Total Productive Maintenance (TPM) to Enhance Overall Equipment Efficiency in Jute Industry-a Case Study." 
22. Sohal, Amrik, et al. "Implementation of OEE-issues and challenges." Competitive and sustainable manufacturing products and services (2010): 1-8.

23. Sharma, R., Kumar, D. and Kumar, P. (2006), "Manufacturing excellence through TPM implementation: a practical analysis", Industrial Management \& Data Systems, Vol. 106 No. 2, pp. 256-280

24. Productivity Improvement using Lean Six Sigma Methodology: A Comprehensive Review Navy Gera* and Er. Harvinder Lal ***M. Tech. Student, Department of Production Engineering, RIET, Phagwara, (Punjab), India **Head, Department of Production Engineering, RIET, Phagwara, (Punjab), India 